NASA Technical Memorandum 100942

AIAA-88-3106

\title{
An Extended Life and Performance Test of a Low-Power Arcjet
}

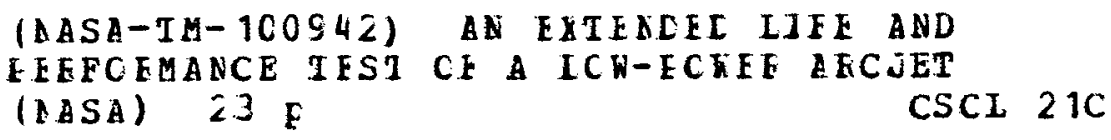

Francis M. Curran and Thomas W. Haag

Lewis Research Center

Cleveland, Ohio

Prepared for the

24th Joint Propulsion Conference

cosponsored by the AIAA, ASME, SAE, and ASEE

Boston, Massachusetts, July 11-13, 1988 


\title{
AN EXTENDED LIFE AND PERFORMANCE TEST OF A LOW-POWER ARCJET
}

\author{
Francis M. Curran and Thomas W. Haag \\ National Aeronautics and Space Administration \\ Lewis Research Center \\ Cleveland, Ohio 44135
}

\begin{abstract}
SUMMARY
An automated, cyclic lifetest was performed to demonstrate the reliability and endurance of a low power dc arcjet thruster. Over $1000 \mathrm{hr}$ and 500 on-off cycles were accumulated which would represent the requirements for about 15 years of on-orbit lifetime. A hydrogen/nitrogen propellant mixture was used to simulate decomposed hydrazine propellant and the power level was nominally $1.2 \mathrm{~kW}$ after the burn-in period. The arcjet operated in a very repeatable fashion from cycle to cycle. The steady state voltage increased by approximately $6 \mathrm{~V}$ over the first $300 \mathrm{hr}$, and then by only $3 \mathrm{~V}$ through the remainder of the test. Thrust measurements taken before, during, and after the test verified that the thruster performed in a consistent fashion throughout the test at a specific impulse of 450 to $460 \mathrm{sec}$. Post-test component evaluation revealed limited erosion on both the anode and cathode. Other thruster components, including graphite seals, appeared undamaged.
\end{abstract}

\section{INTRODUCTION}

Arcjets were first considered for space propulsion three decades ago, and initial research and technology efforts continued into the mid 1960's. During this period, NASA's interest in missions requiring primary electric propulsion was high, so a majority of the resources available were directed toward developing a $30 \mathrm{~kW}$ class hydrogen arcjet (refs. 1 to 4 ). Some effort was also made to modify one of these engines to operate on ammonia. Auxiliary propulsion was also considered as both 1 and $2 \mathrm{~kW}$ arcjets were run successfully, once again on hydrogen, at the Plasmadyne Corporation (refs. 5 and 6). A low level effort to operate at these power levels on alternate propellants such as nitrogen and ammonia met with little success (ref. 7 ). The results of these early programs were reviewed by Wallner and Czika in 1965 (ref. 8).

Over the past 5 years, interest in the arcjet thruster has been rekindled. Recent low power arcjet research has focused on the development of a thruster to replace the monopropellant hydrazine and resistojet thruster currently in use for north-south stationkeeping (NSSK) of geosynchronous communications satellites. Under current programs, arcjet operation on storable propellants has been demonstrated over a wide range of powers and flow rates (refs. 9 to 14). These same studies have also demonstrated that specific impulse values in the range of 400 to $550 \mathrm{sec}$ can be obtained given the conditions expected on a typical stationkeeping application. A pulse width modulated power supply, with an integral high voltage impulse ignition circuit has been used with flow stabilized arcjets to demonstrate consistent, reliable starting and transition to steady state operation (refs. 15 to 18). Preliminary studies to evaluate plume impacts have been completed (refs. 19 and 20), and further work is in progress. Similarly, the effects of electromagnetic emissions (EMI), both radiated and conducted, are being addressed. While many of the technical barriers to practical arcjet application have been addressed, it was necessary 
to demonstrate reliable operation over the many hundreds of hours of operation that will be accumulated in short duty cycles in the NSSK scenario (refs. 21 and 22). To this point, little extended testing has been performed. A single start, $200 \mathrm{hr}$ continuous test on hydrogen first demonstrated that long term operation was possible (ref. 6). A more recent test produced $104 \mathrm{hr}$ of operation at $0.9 \mathrm{~kW}$ on a hydrogen/nitrogen mixture simulating the decomposition products of hydrazine (ref. 14). A series of 20 to $60 \mathrm{hr}$ tests designed to give parametric performance and erosion measurements using hydrazine decomposition products at power levels between 1.2 and $2.0 \mathrm{~kW}$ has al so been performed (refs. 13 and 22).

A preliminary report of the results of an ongoing, autonomous, cyclic lifetest of a low power arcjet thruster was recently presented (ref. 23). This paper presents final results from that test. A hydrogen/nitrogen gas mixture was used as the propellant to simulate the decomposition products of hydrazine. The power level, mass flow, and cycle duration were chosen to approximate conditions expected in a near-term, north-south stationkeeping application. Descriptions of the vacuum facilities, arcjet thruster both before and after the test, and thruster diagnostics are included. Data pertaining to arcjet operating characteristics and performance, along with other observed phenomena such as burn-in, are documented and discussed. Projections for realistic mission expectations are presented and suggestions for areas of further work are made.

\section{APPARATUS}

The arcjet used throughout the test was of the conventional constrictedarc design. Figure 1 shows a cutaway schematic of the thruster used in the test. The anode/nozzle insert was made from 2 percent thoriated tungsten. The converging and diverging sides of the nozzle were both conical with half angles of $30^{\circ}$ and $20^{\circ}$, respectively. The constrictor was $0.41 \mathrm{~mm}$ in length and $0.64 \mathrm{~mm}$ in diameter. A photomicrograph of the converging side of the anode with a view down the constrictor is shown in figure 2 . The diverging side was similar in appearance.

Arc:stability was achieved by means of a propellant vortex flow pattern. A molybdenum gas injector disk with two tangential holes $0.34 \mathrm{~mm}$ in diameter spun gas around the cathode immediately upstream of the arc constrictor to provide the vortex flow. Upstream of the injection disk was a boron nitride front insulator which coaxially centered the cathode within the arc chamber. Longitudinal grooves milled into the outer surface of the insulator provided a path in which the propellant was regeneratively heated by the anode housing and insulator before being injected into the arc. The front insulator, injection disk, and nozzle insert were enclosed in an anode housing made from titaniated-zirconiated molybdenum (TZM). Graphite foil gaskets were used throughout the assembly to provide both internal and external sealing. High pressure external seals were reinforced by raised circular grooves machined into the gasket seats ( $f i g .1$ ).

The rear half of the arcjet consisted of a boron nitride insulator which anchored the cathode rod and propellant supply tube. A modified compression type gas fitting was used in positioning the cathode rod for the proper arc gap. When tightened, the cathode became locked in position and was sealed against propellant leakage. The propellant gas for the arcjet entered from 
one side of the rear insulator. The propellant tube was threaded into a cylindrical steel anchor located within the insulator. The anchor was bored through axially to allow passage of the cathode and its insulating sheath. This unique design allowed the propellant tube to be electrically isolated from both the anode and cathode.

The front half of the rear insulator contained an inconel spring and compression plunger. Force from the spring was used to compress internal seals, thereby channeling all propellant through the injector disk and maximizing vortex intensity. The machining tolerances were set to accommodate internal. thermal expansion over the entire heating and cooling cycle. The rear insulator assembly was joined to the anode housing using two molybdenum flanges, a stainless steel collar, and four bolts. The flanges were designed to flex slightly to maintain uniform pressure over this joint.

The cathode was made from a 2 percent thoriated tungsten rod $3.2 \mathrm{~mm}$ in diameter and approximately $190 \mathrm{~mm}$ in length. The tip was initially ground to a $30^{\circ}$ half angle and then polished to remove any rough edges and give the cathode tip a bullet shape as shown in figure 3 .

A photograph of the arcjet engine prior to assembly is shown in figure 4 . The arc gap was set by moving the cathode forward until it contacted the anode, measuring the entire length, withdrawing the cathode rod to the desired distance, and then tightening the modified compression fitting. The gap was set to $0.58 \mathrm{~mm}$. The lifetest was performed in. a small bell jar facility, shown in figure 5. The vacuum chamber was $0.64 \mathrm{~m}$ in length and $0.64 \mathrm{~m}$ in diameter. $A$ single mechanical roughing pump with a $21000 \mathrm{~L} / \mathrm{min}(730 \mathrm{cfm})$ capacity was used in this vacuum system. In operation, an ambient pressure of approximately 0.75 torr $(100 \mathrm{~Pa})$ was maintained at maximum propellant flow.

Propellant consisted of a hydrogen and nitrogen gas mixture at a stoichiometric ratio of $2: 1$, simulating decomposed hydrazine. The gases were stored and metered separately, then mixed in the propellant feed line to the thruster. Flow regulation was achieved through the use of a two channel mass flow control system. Each channel had a 0 to $10 \mathrm{~L} / \mathrm{min}$ capacity and could be operated from a central console, or remotely through an external set point.

A pulse width modulated power supply with fast current regulation was used throughout the test. This unit had an open circuit voltage of $175 \mathrm{Vdc}$ and a maximum current output of approximately $12.0 \mathrm{~A}$. The power supply had a built in high voltage starting pulse generator to initiate arc breakdown. This circuit could produce a $4 \mathrm{kV}$. pulse once every second until arc ignition was achieved. Once breakdown occurred, the main power supply took over to sustain the arc, and the pulse circuit stopped when positive current was detected. While very high voltages could be obtained with the starting circuit, the total energy content of each pulse was too small to cause electrode damage.

Both the flow control system and the arcjet power supply were configured so that they could be operated remotely. To provide automatic cycling capability, a small programmable controller was installed at the bell jar facility. This controller had the capacity of up to 16 input and 12 output relays and was interfaced to cycle the flow control system and the power supply in a programmed timing sequence. Thruster arc voltage was monitored by an analog panel meter with dual set points that were input to the controller. The high voltage set point was chosen to be approximately $30 \mathrm{~V}$ above the normal 
operating voltage of the arcjet, and would indicate if the arc had gone out. The low voltage set point was chosen to be approximately $20 \mathrm{~V}$ below the normal arc operating voltage to indicate arc anode attachment upstream of the throat, a condition commonly referred to as low mode operation (ref. 10). At the beginning of a new cycle, the controller was programmed to ignore set point violations for the first $60 \mathrm{sec}$ of operation, allowing the arcjet time to start and stabilize. After this period, any set point violation instigated a shutdown of the power supply, suspending the test. A manual system reset was provided to return the system to initial conditions so that resumed testing would always begin with a new cycle.

All thrust measurement and performance evaluations, as well as the lifetest in the bell jar, were carried out in the Electric Power Laboratory at the NASA Research Center. Due to the availability of the larger vacuum facilities, thrust measurement testing took place in one of two large vacuum tanks. Both were equipped with diffusion pumps and the background pressure in each was below $3.5 \times 10^{-4}$ torr $(0.0466 \mathrm{~Pa})$ at the flow rates used in the performance tests. Regardless of the location, all thrust measurement, propellant metering and power equipment was moved with the arcjet to the facility being used in order to provide experimental consistence data. The thrust stand was of the flexure displacement type and was calibrated in situ before each test. Further details: on the thrust measurement instrumentation are presented el sewhere (ref. 17).

In all facilities, an eight channel strip chart recorder was used to record arc voltage, arc current, propellant flow rates, and propellant line pressure. In performance testing, thrust was recorded on one of the channels, while in the belljar facility that channel was used to record the temperature on the rear insulator of the arcjet. The arc current was measured using a Hall-effect current probe. Once calibrated, the current measurement was accurate to within $\pm 0.1 \mathrm{~A}$. The arc voltage was taken across a 10:1 voltage divider. An isolation amplifier was used between the divider and the chart recorder. A digital multimeter was used to provide periodic, redundant voltage measurements. These were taken directly across the power feedthroughs to the arcjet.

\section{Operating Parameters and Procedure}

The arcjet lifetest was designed to approximate a geosynchronous stationkeeping application. For simplicity, a fixed operating point was chosen for both the mass flow rate and the current. The operating parameters in an actual flight application will depend on the type of spacecraft and the mission requirements. A mission analysis for a proposed communications satellite revealed that a blowdown propellant system would result in a 20 percent drop in propellant mass flow rate to an end of life value of approximately $4 \times 10^{-5}$ $\mathrm{kg} / \mathrm{sec}$ for a 300-hr propulsion mission. Since the lowest mass flow rate represents a worst case for both arc stability and thruster temperature, this value was chosen as the mass flow rate of the simulated hydrazine gas mixture to be used throughout the test. A current of $11 \mathrm{~A}$ produced a power level slightly greater than $1.1 \mathrm{~kW}$ at the end of a burn-in period. Since arc voltage was expected to increase over the course of the test due to cathode recession, and because the spacecraft power available for each thruster will likely be close to $1.2 \mathrm{~kW}$, an $11 \mathrm{~A}$ current level was chosen for the test. A 50 percent duty cycle was chosen with the arcjet on for $2 \mathrm{hr}$, and off for $2 \mathrm{hr}$. The intent 
was to allow for cooling time in order that cold starting reliability could be demonstrated. To improve the between-cycle cooling further, the propellant flow was initiated 5 min before the start of each cycle and left on for $5 \mathrm{~min}$ after the arcjet power supply was shut off. With these measures the temperature taken on the rear insulator always returned to between 40 and $45^{\circ} \mathrm{C}$ from an end of cycle temperature of $310^{\circ} \mathrm{C}$. The $5 \mathrm{~min}$ propellant flow period prior to each cycle served dual purpose in that it assured an equilibrium flow rate had been attained before the thruster was operated. This length of time was found to be unnecessary for this purpose. In àn actual application, in which the hydrazine catalyst bed is very close to the thruster and there is little total dead volume, the equilibration period is expected to be on the order of a few seconds. The programmable controller was configured to shut down the test if the arcjet did not operate within the established voltage limits 1 min after ignition. Due to the large quantity of gas to be used over the course of the test, propellants were stored in separate banks of $K$ bottles and necessary changeovers were made during the off cycles.

The arcjet was removed from the bell jar at specified times in order to determine thruster performance as operating time had accumulated. Before any measurements were taken, all electronics, along with cooling water to the thrust stand, were turned on and allowed to equilibrate. The mass flow controllers were calibrated to provide +1 percent accuracy. The current probe was then calibrated with a current shunt prior to arcjet operation. Thrust stand calibration was performed before and after each run using weights suspended on a monofilament line attached to a windlass. Once thrust stand calibration was accomplished, cold flow thrust measurements were taken for each mass flow rate to be tested. The cold flow specific impulse obtained was compared to previous tests to insure no major propellant leaks were present in the arcjet or flow system. The arcjet.was then started and thrust measurements were obtained. Thrust data were taken only after the arcjet had reached steady state for a given set of conditions.

\section{RESULTS AND DISCUSSION}

As previously discussed, the arcjet life test was automated for cyclic operation to approximate the NSSK role on a geosynchronous communications satellite. In addition, the operating characteristics and performance were carefully measured in high vacuum facilities at points before the arcjet burn-in, after the 144th and 335th cycles, and at the conclusion of testing. The data from these tests are tabulated in tables I to IV, respectively.

\section{Burn-in Period}

Prior experience with arcjet thrusters has shown that operational stability is manifested in the steadiness of the plume and smoothness of the voltage trace. After a brief performance check once the thruster was assembled, a 14 cycle burn-in period was found to be necessary for this thruster before consistent operation was obtained. A few of the cycies during this period showed stable voltage readings, but others were characterized by fluctuations in the voltage trace. Some of these voltage excursions were very rapid, as shown in figure 6(a), while others took the form of step changes in voltage as shown in figure $6(b)$. All of these excursions were accompanied by plume motion in the form of rotation and/or lengthening. While no positive explanation for these 
observations has been verified, it is the author' 'opinion that they are caused by motion of the arc spot at the cathode tip. The largest of the observed excursions was $15 \mathrm{~V}$. Fluctuations in the voltage due to low mode attachment at the anode are typically greater than $40 \mathrm{~V}$ and accompanied by extreme changes in the plume geometry, as the attachment region moves upstream into the constrictor. This phenomena was not observed. Rather, the data suggests that the arc attachment point does not stabilize and become repeatable until a near-steady state cathode shape has developed. At the start of one cycle during the burn-in, low mode attachment did occur. In this mode the operating voltage was between 50 and $60 \mathrm{~V}$ at the end of the first minute. This violated the low voltage limit and shut down the test before any apparent damage was done to the thruster. A system reset resulted in a normal starting sequence. The steady state operating voltage increased from $96 \mathrm{~V}$ to about $101 \mathrm{~V}$ over the course of the burn-in period. The above suggests that somewhat erratic thruster behavior can be expected until the cathode nears a steady state shape.

\section{Operating Characteristics}

The lifetest cycles following the burn-in period were characterized by stable and consistent steady state arcjet operation. Four voltage traces from different points in the test are shown in figure 7 to demonstrate this point. At the start of each cycle, a brief period of high mode voltage fluctuation was observed. This behavior is common to arcjet operation and is presumably a result of the arc not immediately attaining an equilibrium position on the cathode tip. The time required for stabilization varied from cycle to cycle, but was never longer than the $5 \mathrm{~min}$ observed at the start of the first cycle, and often was very brief (see fig. 7). In every case, the voltage rose to within 98 percent of its steady state value within 5 min of ignition. Once steady state had been attained, no flickering or unsteadiness of the plume was observed. Careful examination of the chart records showed no evidence of voltage fluctuations at any point in the test after the above-mentioned starting transient. Taken together, these facts indicate that the arc seated in a repeatable fashion in the steady state operational mode from cycle to cycle.

Over the course of the lifetest, the steady state operating voltage rose from an initial value of approximately $101 \mathrm{~V}$ to a post-test value of $110.6 \mathrm{~V}$, as shown in figure 8 . This increase was likely due to recession of the cathode tip as the rate of increase decreased with time. The recession will be documented in a following section. In the first $300 \mathrm{hr}$ of operation, the increase totaled more than $6 \mathrm{~V}$, while in the final $700 \mathrm{hr}$, the rise was only $3 \mathrm{~V}$. This trend indicates that a limiting value should not be expected in a normal mission time frame, and so the slight voltage increase, at constant current, would have to be addressed from a mission-impacts standpoint. The cathode recession, however, does not appear to represent a life limiting mechanism for anticipated mission lifetimes.

The arcjet exhibited typical negative voltage-current characteristics at each of the performance check points. An example is shown in figure 9 . For clarity, data taken at a single flow rate is plotted. The data in the figure shows that the voltage increase over time was similar at current levels other than that used in the actual lifetest cycles.

Two mid-cycle shutdowns did occur during the course of the lifetest. In each case, the chart recorder traces indicated no arcjet-related operational 
problems that would cause the controller to shut down the power supply. One of the occurrences was traced to an inadvertent activation of a facility safety relay. The other shutdown remains unexplained, but it is likely that the cause was similar. In both cases, the arcjet cycling program was restarted, and the next cycles displayed no anomalous behavior. Also, after a facility modification, the power supply relay was not reconnected properly, and the power supply remained on at the end of the cycle as the propellant shut off. This caused the arcjet to slip momentarily into low mode. The problem was quickly corrected with no apparent damage to the thruster, as no difference was observed in the operating voltage on the next cycle.

\section{Starting Phenomena}

At the start of the fourth cycle in the bell jar facility, the power supply came on as anticipated but arcjet ignition did not occur. Examination of the starting pulse with a fast, storage oscilloscope revealed a distortion in the form of an interruption of the voltage rise that corresponded with a current spike. This is shown in figure 10. This figure indicates the occurrence of a brief, pre-ignition corona discharge which was also visible near the flanges on the outside of the thruster. More extensive insulation of the cathode connection, lead, and feedthrough, was not effective in eliminating the problem. Fortunately, the current drawn by the discharge was only about $0.1 \mathrm{~A}$, and of short duration so it did not completely discharge the inductor in the starting circuit. Thus, the voltage continued to rise after the corona had occurred. To continue testing, the energy available in the starting circuit was simply increased so that the maximum voltage attainable following the discharge was sufficient to start the arc. This phenomenon was observed periodically throughout the lifetest and was definitely related to the high background pressure in the bell jar as it was not observed during the starting pulses monitored in the high vacuum performance testing facilities.

Starting has been shown to be a statistical phenomena that depends on electrode geometry, mass flow rate, and rate of voltage rise in the ignition pulse (ref. 18). Only rarely during this test was more than one pulse needed to start the thruster. At one point in the test, however, an undistorted pulse of $4 \mathrm{kV}$ was observed which did not start the arcjet.

\section{Performance}

A photograph of the arcjet operating in the final performance check is shown in figure 11. At this point, and at the two performance checks made during the test, data was taken over a range of both power and mass flow rate. Before the burn-in period, the voltage varied rapidly, so performance measurements were taken only at the flow rate and current level to be used during the lifetest. Specific impulse is plotted versus the ratio of power to mass flow rate. in figure $12(a)$. At any given power to mass flow rate, the data fell within a band of no more than $15 \mathrm{sec}$ of specific impulse. At many points, the scatter was less than $10 \mathrm{sec}$. Perhaps most interesting is the fact that the data point taken before the burn-in period is centered with the other data. The voltage at a fixed current and mass flow rate was lower at this point than later in testing, $23 \mathrm{~V}$ when compared to the end of test data. The performance as indicated by specific impulse versus the power to mass flow rate ratio, however, was nearly identical. This indicates that energy input mechanisms are 
not very dependent upon small changes in arc length observed over the course of this test. From the systems level point of view, a more meaningful relationship is the specific impulse versus the thrust to power ratio. This is plotted, from the same data set, in figure 12 (b).

No evidence of a trend indicating thruster performance degradation with time can be found in either of the plots shown in figure 12. Clearly then, the data indicates that reasonable performance estimates can be obtained for mission planning if given the propellant blowdown range and power availability on a specific spacecraft as well as the power processor efficiency. The data in these figures and in tables I-IV also show that specific impulse values in the range of $450 \mathrm{sec}$ should be attainable at the power levels and mass flow rates typical of communications satellites.

\section{Post-Test Component Condition}

As expected from the increase in the arcjet operating voltage observed during the test, the post test component analysis revealed significant recession of the originally pointed tip of the cathode. The changes are illustrated in the series of photographs in figure 13 and the sketch in figure 14 . The cratered appearance the tip has assumed by the conclusion of the lifetest is shown in figure 13(a) under low magnification. The crater was slightly more than $0.8 \mathrm{~mm}$ in diameter, as was the decrease in cathode length. The crater itself, as well as the rim and shoulder, were covered with granular material (see fig. 13(b)) most likely due to cathode spot motion during the starting instability. No evidence was found of the dendrite formation seen in arcjet testing at higher power levels (ref. 24). Within the main crater on the tip was a second, smaller crater which was obviously molten and the point of arc attachment during steady state operation. This is shown under higher magnification in figure $13(\mathrm{c})$. . The crater is roughly circular with a diameter of approximately $0.16 \mathrm{~mm}$. Structures of this type have been documented before. In a recently reported test (ref. 16), a cathode of the same initial geometry as the one used in the lifetest was run in a similar thruster at a current level slightly below that used in the lifetest. As this cathode was not run for many hours, the total decrease in cathode length was much less than that observed in the lifetest. A cathode crater documented in this test was nearly identical in size and shape to the one on the lifetest cathode. These observations are clear evidence that the processes ongoing at the point of emission, at steady state, are independent of the cathode recession and of the gross dimensions of the larger tip crater. In both tests, the craters were composed of a series of concentric rings of material leading down to their centers. These appear to have been formed as the molten pool resolidified after the arc was extinguished. In the photograph of the lifetest cathode, a crack split the spot attachment zone and this had obviously occurred after resolidification was complete. The total mass loss from the tip was $6.6 \times 10^{-6} \mathrm{~kg}$.

The post-test condition of the anode is illustrated by the series of photomicrographs shown in figure 15. As in the case of the cathode, the degradation shown is very similar to that described in the previous report on arcjet components run for a much shorter period of time. Figure 15(a) shows a network of stress cracking and discoloration near the constrictor entrance. Some areas of the converging side of the nozzle upstream of the constrictor were covered with a thin raised layer of crystalline material indicating some surface melting. As suggested in the previous report (ref. 16), it is likely 
that the arc initially strikes upstream of the constrictor between the cathode and the converging side of the anode/nozzle and is quickly pushed out to its equilibrium position by the flow field. Some of the observed melting probably occurs during this period as the anode attachment zone in the high pressure region is expected to be in a concentrated spot mode. Melting could also have occurred during the two brief periods of low mode operation previously discussed. A view taken at higher magnification from the diverging side (fig. $15(b)$ ) shows that molten material had resolidified in the constrictor, and that less melting had occurred downstream near the exit of the constrictor. A magnified view of the exit from the diverging side (fig. 15(c)) shows that some molten material migrated to the nozzle side, but that the exit itself was essentially intact. The microcracks traversing the length of the constrictor have also been previously reported (refs. 13 to 16). While the changes in the anode appear to be extensive, it must be noted that they did not lead to any gross performance changes during the testing. That similar changes have been documented after much shorter periods of testing indicates that much of the stress cracking and melting probably occurred early in the test. This damage has been unavoidable in testing to date, but seems to have little effect on the reliability or performance of the arcjet.

Visual inspection of the graphite seals, injection disk, and compression spring revealed.no deterioration. This was also true of the internal insulators, fittings, holding brackets, and the anode housing. The boron nitride rear insulator showed a discoloration typical of extended operations at elevated temperatures.

\section{CONCLUDING REMARKS}

An autonomous life test of a low power, dc arcjet thruster has been successfully completed. More than $1000 \mathrm{hr}$ of operation were accumulated in $2 \mathrm{hr}$ cycles. A nominal power level of $1.2 \mathrm{~kW}$ and a propellant mixture of nitrogen and hydrogen simulating the decomposition products of hydrazine were used to approximate a NSSK mission for a geosynchronous communications satellite. The mass flow rate of the propellant was fixed near the lower limit expected in a typical blowdown system after 5 years of operation.

Stable, consistent arcjet operation was obtained after a 14 cycle burn-in period. Each cycle was characterized by a brief period of voltage fluctuation that is believed to be caused by motion of the arc attachment spot at the cathode tip before it moves to its equilibrium position. After this, the arcjet operated in a stable fashion with no voltage excursions observed during steady state operation. A rapid increase in steady state arc voltage was observed during the burn-in period signaling rapid tip recession. The rate of increase lessened throughout the remainder of the test indicating that the tip was approaching a stable shape. After the burn-in period, a rise of about $9.6 \mathrm{~V}$ was observed over the course of the test, and of this, only $3 \mathrm{~V}$ occurred in the last $700 \mathrm{hr}$. This trend and the condition of the cathode after the test indicated that cathode recession should not be a life limiting process over typical mission durations. A system level decision will be needed to determine the optimum technique to accommodate the voltage increase at fixed current.

A facility-related corona discharge phenomenon during starting pulses was observed in the bell jar facility. This phenomenon was never eliminated and 
ignition was accomplished by increasing the peak pulse voltage. While the pre-ignition discharge did not compromise test integrity, it did point out that future tests should include periodic checks of breakdown voltage in high vacuum facilities to accurately assess starting characteristics over time.

An examination of the thruster components after the test showed no unusual wear. Molten material and microcracks were documented in the vicinity of the constrictor in the anode, but this was no more severe than that observed in tests of much shorter duration. This, like the cathode degradation, does not appear to be a life-limiting factor over realistic operating times. The injector disk, graphite seals, and compression spring showed no evidence of degradation while the boron nitride exhibited only the slight surface discoloration typical of operation at elevated temperature.

Finally, performance measurements during and after the test showed that both thrust and specific impulse values, at a given current and mass flow rate, had increased significantly from those obtained before the burn-in period. This is attributed to the increase in power to the device caused by the voltage rise due to cathode recession. At a given power to mass flow rate; however, the specific impulse values were very similar in the performance checks, indicating that no change in operating mode occurs due to the recession of the cathode. From the performance, it is clear that specific impulse values in the range of $450 \mathrm{sec}$ can be expected at power levels available on commercial communications satellites, and that predictable, reliable operation can reasonably be assumed for long term mission applications.

\section{REFERENCES}

1. John, R.R., Connors, J.F., and Bennett, S., "Thirty Day Endurance Test of a $30 \mathrm{~kW}$ Arcjet Engine," AIAA Paper 63-274, June 1963.

2. John, R.R., "Thirty Kilowatt Plasmajet Rocket-Engine Development," RAD-TR-64-6, Avco Corp., Wilmington, MA, NASA CR-54044, 1964.

3. Todd, J.P., and Sheets, R.E., "Development of a Regeneratively Cooled 30-kW Arcjet Engine," AIAA Journal, Vol. 3, No. 1, Jan. 1965, pp. $122-126$.

4. Todd, J.P., "30 kW Arcjet Thruster Research," APL-TDR-64-58, Giannini Scientific Corp., Santa Ana, CA, Mar. 1964. (Avail. NTIS, AD-601534.)

5. Ducati, A.C., Humpal, H., Meltzer, J., Muehlberger, E., Todd, J.P., and Waltzer, H., "l-kW Arcjet-Engine System-Performance Test," Journal of Spacecraft and Rockets, Vol. 1, No. 3, May-June 1964, pp. 327-332.

6. McCaughey, 0.J., Geideman, W.A., Jr., and Muller, K., "Research and Advanced Development of a $2 \mathrm{~kW}$ Arc-Jet Thruster," GRC-1646, Plasmadyne Corp., Santa Ana, CA, NASA CR-54035, 1963.

7. Shepard, C.E., and Watson, V.R., "Performance of a Constricted-Arc Discharge in a Supersonic Nozzle," Physico-Chemical Diagnostics of Plasmas, T.P. Anderson, R.W. Springer, and R.C. Warder, Jr., eds., Northwestern University Press, 1964, pp. 261-272. (AIAA Paper 63-380). 
8. Wallner, L.E., and Czika, J. Jr., "Arc-Jet Thrustor for Space Propulsion," NASA TN D-2868, 1965.

9. Nakanishi, S., "Experimental Performance of a 1 Kilowatt Arcjet Thruster," AIAA Paper 85-2033, Oct. 1985. (NASA TM-87131.)

10. Curran, F.M., and Nakanishi, S., "Low Power dc Arcjet Operation with Hydrogen/Nitrogen Propellant Mixtures," AIAA Paper 86-1505, June 1986. (NASA TM-87279.)

11. Hardy, T.L., and Curran, F.M., "Low Power dc Arcjet Operation with Hydrogen/Nitrogen'/Ammonia Mixtures," AIAA Paper 87-1948, June 1987. (NASA TM-89876.)

12. Knowles, S.C., Smith, W.W., Curran, F.M., and Haag T.W., "Performance Characterization of a Low Power Hydrazine Arcjet," AIAA Paper 87-1057, May 1987.

13. Knowles, S.K., "Arcjet Thruster Research and Technology, Phase I, Final Report," 87-R-1175, Rocket Research Co., Redmond, WA, Sept. 1987.

14. Simon, M.A., Knowles, S.C., Curran, F.M., and Hardy, T.L., "Low Power Arcjet Life Issues," AIAA Paper 87-1059, May 1987.

15. Gruber, R.P., "Power Electronics for a 1-kW Arcjet Thruster," AIAA Paper 86-1507, June 1986. (NASA TM-87340.)

16. Curran, F.M., and Haag, T.W., "Arcjet Component Conditions Through a Multistart Test," AIAA Paper 87-1060, May 1987. (NASA TM-89857).

17. Haag, T.W., and Curran, F.M., "Arcjet Starting Reliability: A Multistart Test on Hydrogen/Nitrogen Mixtures," AIAA Paper 87-1061, May 1987. (NASA TM-89867.)

18. Sarmiento, C.J., and Gruber, R.P., "Low Power Arcjet Thruster Pulse Ignition," AIAA Paper 87-1951, July 1987. (NASA TM-100123).

19. Zana, L.M., "Langmuir Probe Surveys of an Arcjet Exhaust," AIAA Paper 87-1950, July 1987. (NASA TM-89924).

20. Carney, L.M., "Evaluation of the Communications Impact of a Low Power Arcjet Thruster," AIAA Paper 88-3105. July 1988.

21. Knowles, S.K., Smith, W.W., Chun, S.I., and Feconda, R.T., "Low Power Hydrazine Arcjets: A System Description for Near-Term Application." 1986 JANNAF Propulsion Meeting, Vol. 1, K.L. Strange and D.S. Eggleston, eds., CPIA-PUBL-455-Vol.1, Chemical Propulsion Information Agency, Johns Hopkins University, Laurel, MD, 1986, pp. 399-408.

22. Knowles, S.K., Personal Communication, Rocket Research Company, Apr. 1988.

23. Curran, F.M., Hardy, T.L., and Haag, T.W., "A Low Power Arcjet Cyclic Lifetest," NASA TM-100233, 1987. 
24. Pivirotto, T., King, D.Q., Deininger, W., and Brophy, J.R., "The Design and Operating Characteristics of a $30 \mathrm{~kW}$ Thermal Arcjet Engine for Space Propulsion," AIAA Paper 86-1508, June 1986.

TABLE I. - ARCJET PERFORMANCE CHARACTERISTICS TAKEN

PRIOR TO THE 14 CYCLE RUN-IN PERIOD

\begin{tabular}{|c|c|c|c|c|c|c|c|c|}
\hline$\underset{A}{\text { Current, }}$ & $\underset{\mathrm{V}}{\text { Vol tage, }}$ & $\begin{array}{c}\text { Power, } \\
\text { kW }\end{array}$ & $\frac{\dot{m},}{\mathrm{~kg} / \mathrm{sec} \times 10^{3}}$ & $\begin{array}{c}\text { Thrust, } \\
\mathbf{N}\end{array}$ & $\begin{array}{l}I_{\text {sp }} \\
\text { sec }\end{array}$ & $\begin{array}{l}\text { "Thrusf: } \\
\text { percent }\end{array}$ & $\begin{array}{c}\mathrm{P} / \dot{\mathrm{m}}_{1} \\
\mathrm{~kW}-\mathrm{sec} / \mathrm{kg}\end{array}$ & $\begin{array}{l}T / P, \\
N / k H\end{array}$ \\
\hline 11.0 & 89.0 & 0.979 & 0.0407 & 0.169 & 422 & 35.0 & 24000 & 0.173 \\
\hline
\end{tabular}

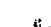

TABLE II. - PERfORMANCE CHARACTERISTICS TAKEN AFTER 144 CYCLES

\begin{tabular}{|c|c|c|c|c|c|c|c|c|}
\hline$\underset{A}{\text { Current. }}$ & $\underset{V}{\text { Vol tage, }}$ & $\begin{array}{c}\text { Power. } \\
\mathrm{kW}\end{array}$ & $\stackrel{\dot{m}_{0}, 0^{3}}{\mathrm{~kg} / \sec \times 10^{3}}$ & Thrust, & $\begin{array}{l}I_{\text {sp }}, \\
\text { sec }\end{array}$ & $\begin{array}{l}\text { nThrust, } \\
\text { percent }\end{array}$ & $\begin{array}{c}\mathrm{P} / \mathrm{m}, \\
\mathrm{kW}-\mathrm{sec} / \mathrm{kg}\end{array}$ & $\begin{array}{l}T / P, \\
N / k W\end{array}$ \\
\hline $\begin{array}{c}99 \\
10 \\
11 \\
12\end{array}$ & $\begin{array}{l}110.5 \\
107.8 \\
107.6 \\
106.9\end{array}$ & $\begin{array}{l}0.994 \\
1.078 \\
1.184 \\
1.283\end{array}$ & 0.0407 & $\begin{array}{r}0.170 \\
.176 \\
.180 \\
.187\end{array}$ & $\begin{array}{l}425 \\
441 \\
452 \\
468\end{array}$ & $\begin{array}{l}34.5 \\
34.3 \\
32.9 \\
32.6\end{array}$ & $\begin{array}{ll}24 & 400 \\
26 & 500 \\
29 & 100 \\
31 & 500\end{array}$ & $\begin{array}{r}0.171 \\
.163 \\
.152 \\
.146\end{array}$ \\
\hline $\begin{array}{r}8 \\
9 \\
10 \\
11 \\
12\end{array}$ & $\begin{array}{l}118.4 \\
114.6 \\
111.9 \\
109.6 \\
108.0\end{array}$ & $\begin{array}{r}.947 \\
1.031 \\
1.119 \\
1.206 \\
1.296\end{array}$ & 0.0455 & $\begin{array}{l}.180 \\
.186 \\
.191 \\
.198 \\
.205\end{array}$ & $\begin{array}{l}402 \\
416 \\
429 \\
444 \\
460\end{array}$ & $\begin{array}{l}36.1 \\
35.6 \\
35.0 \\
34.8 \\
34.8\end{array}$ & $\begin{array}{ll}20 & 800 \\
22 & 700 \\
24 & 600 \\
26 & 500 \\
28 & 500\end{array}$ & $\begin{array}{l}.190 \\
.180 \\
.171 \\
.164 \\
.158\end{array}$ \\
\hline $\begin{array}{r}9 \\
10 \\
11 \\
12\end{array}$ & $\begin{array}{l}118.0 \\
115.1 \\
112.6 \\
111.1\end{array}$ & $\begin{array}{l}1.062 \\
1.151 \\
1.240 \\
1.333\end{array}$ & 0.0497 & $\begin{array}{l}.197 \\
.204 \\
.212 \\
.222\end{array}$ & $\begin{array}{l}404 \\
419 \\
435 \\
454\end{array}$ & $\begin{array}{l}35.5 \\
35.3 \\
35.4 \\
36.0\end{array}$ & $\begin{array}{ll}21 & 400 \\
23 & 200 \\
25 & 000 \\
26 & 800\end{array}$ & $\begin{array}{l}.185 \\
.177 \\
.171 \\
.166\end{array}$ \\
\hline
\end{tabular}

TABLE III. - PERFORMANCE CHARACTERISTICS TAKEN AFTER 335 CYCLES

\begin{tabular}{|c|c|c|c|c|c|c|c|c|}
\hline $\begin{array}{c}\text { Current, } \\
\text { A }\end{array}$ & Voltage, & $\begin{array}{c}\text { Power, } \\
\text { KW }\end{array}$ & $\mathrm{mg} / \dot{m}_{1}, 10^{3}$ & $\begin{array}{c}\text { Thrust, } \\
N\end{array}$ & $\begin{array}{l}I_{\text {sp }}, \\
\text { sec }\end{array}$ & $\begin{array}{l}{ }^{{ }^{2} \text { Thrust, }} \\
\text { percent }\end{array}$ & $\begin{array}{c}\mathrm{P} / \dot{\mathrm{m}}, \\
\mathrm{kW}-\mathrm{sec} / \mathrm{kg}\end{array}$ & $\begin{array}{l}T / P \text {, } \\
N / k W\end{array}$ \\
\hline $\begin{array}{r}8 \\
9 \\
10 \\
11 \\
12\end{array}$ & $\begin{array}{l}117.5 \\
113.8 \\
111.2 \\
108.6 \\
106.8\end{array}$ & $\begin{array}{l}0.940 \\
1.025 \\
1.112 \\
119.5 \\
1.282\end{array}$ & 0.0407 & $\begin{array}{r}0.165 \\
.170 \\
.178 \\
.180 \\
.186\end{array}$ & $\begin{array}{l}413 \\
425 \\
447 \\
452 \\
467\end{array}$ & $\begin{array}{l}34.4 \\
33.5 \\
34.3 \\
32.6 \\
32.5\end{array}$ & $\begin{array}{ll}23 & 100 \\
25 & 200 \\
27 & 300 \\
29 & 400 \\
31 & 500\end{array}$ & $\begin{array}{r}0.175 \\
.165 \\
.160 \\
.151 \\
.145\end{array}$ \\
\hline $\begin{array}{r}8 \\
9 \\
10 \\
11 \\
12\end{array}$ & $\begin{array}{l}121.8 \\
118.2 \\
114.9 \\
112.7 \\
110.8\end{array}$ & $\begin{array}{l}.974 \\
1.066 \\
1.149 \\
1.240 \\
1.330\end{array}$ & 0.0455 & $\begin{array}{l}.176 \\
.184 \\
.190 \\
.198 \\
.206\end{array}$ & $\begin{array}{l}396 \\
413 \\
426 \\
444 \\
462\end{array}$ & $\begin{array}{l}34.0 \\
33.9 \\
33.5 \\
33.8 \\
34.3\end{array}$ & $\begin{array}{ll}21 & 400 \\
23 & 400 \\
25 & 300 \\
27 & 300 \\
29 & 200\end{array}$ & $\begin{array}{l}.181 \\
.173 \\
.166 \\
.160 \\
.155\end{array}$ \\
\hline $\begin{array}{r}8 \\
9 \\
10 \\
11 \\
12\end{array}$ & $\begin{array}{l}125.7 \\
121.8 \\
118.4 \\
116.0 \\
114.2\end{array}$ & $\begin{array}{l}1.006 \\
1.096 \\
1.184 \\
1.276 \\
1.370\end{array}$ & 0.0497 & $\begin{array}{r}.192 \\
.199 \\
.207 \\
.214 \\
.222\end{array}$ & $\begin{array}{l}394 \\
408 \\
424 \\
439 \\
455\end{array}$ & $\begin{array}{l}35.6 \\
35.0 \\
35.2 \\
35.0 \\
35.1\end{array}$ & $\begin{array}{ll}20 & 200 \\
22 & 100 \\
23 & 800 \\
25 & 700 \\
27 & 600\end{array}$ & $\begin{array}{r}.191 \\
.182 \\
.174 \\
.167 \\
.162\end{array}$ \\
\hline
\end{tabular}


TABLE IV. - PERFORMANCE CHARACTERISTICS TAKEN AFTER CONCLUSION OF 502 CYCLES

\begin{tabular}{|c|c|c|c|c|c|c|c|c|}
\hline$\underset{A}{\text { Current, }}$ & $\begin{array}{c}\text { Vol tage, } \\
V\end{array}$ & $\begin{array}{c}\text { Power, } \\
\text { kW }\end{array}$ & $\stackrel{\dot{m}}{\mathrm{~kg} / \mathrm{sec} \times 10^{3}}$ & Thrust, & $\begin{array}{l}I_{s p} \text {, } \\
\text { sec }\end{array}$ & $\begin{array}{l}\text { nThrust, } \\
\text { percent }\end{array}$ & $\begin{array}{c}\mathrm{P} / \dot{\mathrm{m}}, \\
\mathrm{kW}-\mathrm{sec} / \mathrm{kg}\end{array}$ & $\begin{array}{l}\mathrm{T} / \mathrm{P} \text {, } \\
\mathrm{N} / \mathrm{kW}\end{array}$ \\
\hline $\begin{array}{r}8 \\
9 \\
10 \\
11 \\
12\end{array}$ & $\begin{array}{l}119.4 \\
115.7 \\
113.0 \\
110.7 \\
109.3\end{array}$ & $\begin{array}{l}0.956 \\
1.041 \\
1.130 \\
1.218 \\
1.311\end{array}$ & $\begin{array}{c}0.0407 \\
\mid\end{array}$ & $\begin{array}{r}0.166 \\
.172 \\
.178 \\
.183 \\
.189\end{array}$ & $\begin{array}{l}417 \\
432 \\
447 \\
460 \\
474\end{array}$ & $\begin{array}{l}34.6 \\
34.2 \\
33.8 \\
33.3 \\
32.9\end{array}$ & $\begin{array}{ll}23 & 500 \\
25 & 600 \\
27 & 800 \\
29 & 900 \\
32 & 200\end{array}$ & $\begin{array}{r}0.174 \\
.166 \\
.158 \\
.150 \\
.144\end{array}$ \\
\hline $\begin{array}{r}8 \\
9 \\
10 \\
11 \\
12\end{array}$ & $\begin{array}{l}123.0 \\
119.1 \\
116.5 \\
114.6 \\
113.3\end{array}$ & $\begin{array}{l}.984 \\
1.072 \\
1.165 \\
1.260 \\
1.360\end{array}$ & 0.0455 & $\begin{array}{l}.182 \\
.188 \\
.194 \\
.200 \\
.205\end{array}$ & $\begin{array}{l}409 \\
421 \\
435 \\
449 \\
460\end{array}$ & $\begin{array}{l}36.1 \\
35.1 \\
34.6 \\
34.2 \\
33.3\end{array}$ & $\begin{array}{ll}21 & 600 \\
23 & 600 \\
25 & 600 \\
27 & 700 \\
29 & 900\end{array}$ & $\begin{array}{l}.185 \\
.175 \\
.167 \\
.159 \\
.151\end{array}$ \\
\hline $\begin{array}{r}8 \\
9 \\
10 \\
11 \\
12\end{array}$ & $\begin{array}{l}127.5 \\
123.2 \\
120.3 \\
118.1 \\
116.5\end{array}$ & $\begin{array}{l}1.020 \\
1.109 \\
1.203 \\
1.299 \\
1.398\end{array}$ & 0.0497 & $\begin{array}{l}.199 \\
.205 \\
.211 \\
.216 \\
.223\end{array}$ & $\begin{array}{l}408 \\
420 \\
433 \\
443 \\
457\end{array}$ & $\begin{array}{l}37.8 \\
37.0 \\
36.3 \\
35.3 \\
34.9\end{array}$ & $\begin{array}{ll}20 & 500 \\
22 & 300 \\
24 & 200 \\
26 & 100 \\
28 & 100\end{array}$ & $\begin{array}{l}.195 \\
.184 \\
.175 \\
.166 \\
.159\end{array}$ \\
\hline
\end{tabular}

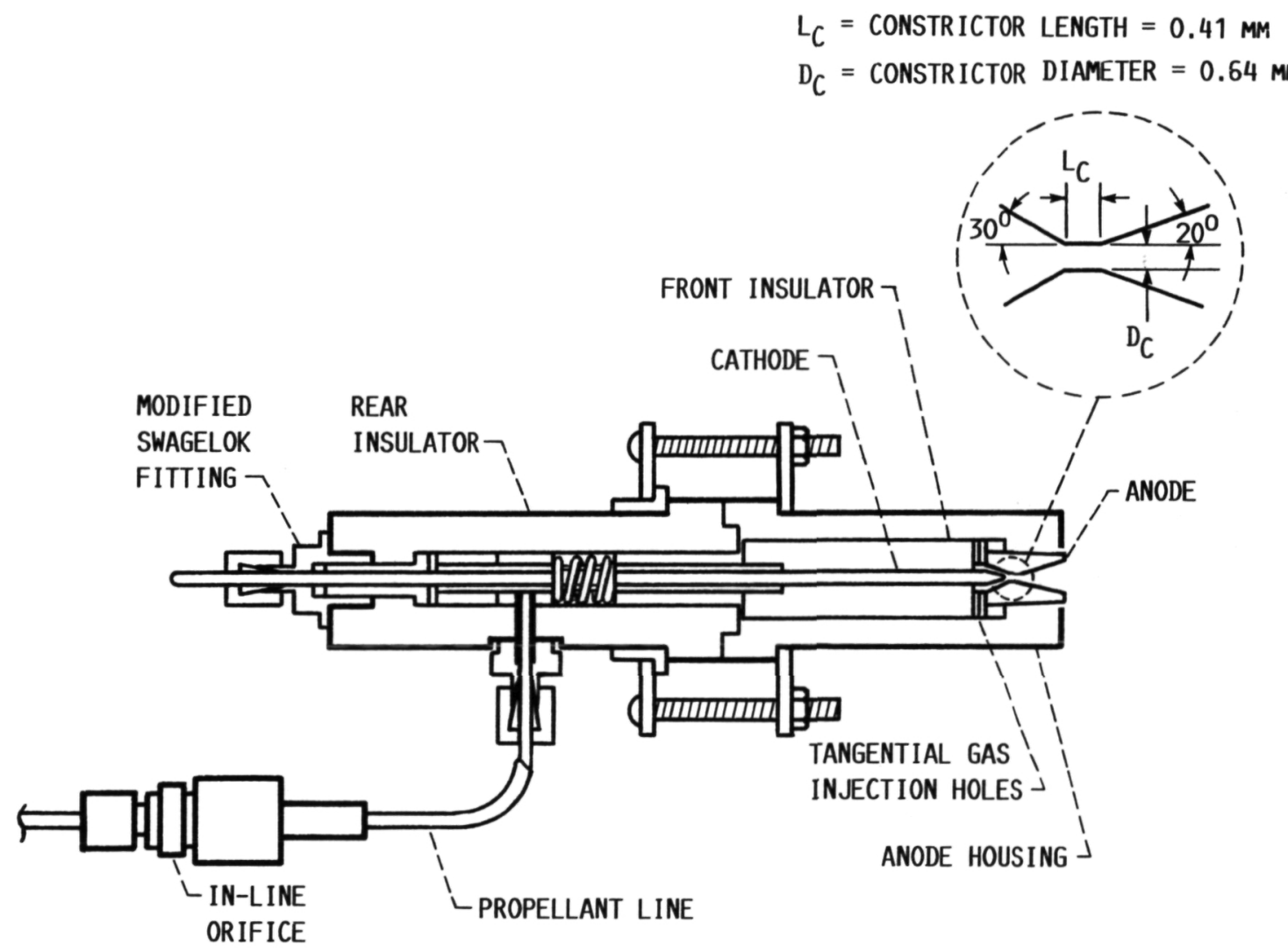

FIGURE 1. - CUTAWAY VIEW OF ARCJET THRUSTER WITH ANODE DIMENSIONS DESCRIBED. 
ORIGINAI PAGE IS

OE ROOR QUALITY

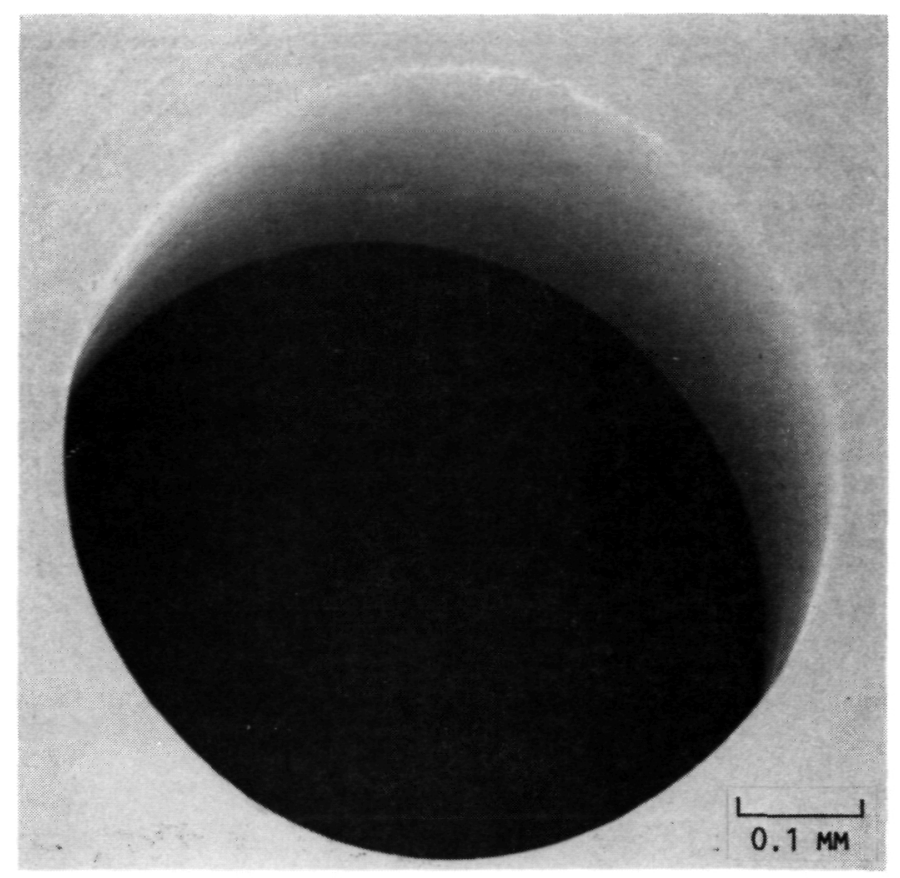

FIGURE 2. - PHOTOMICROGRAPH OF CONVERGING SIDE OF ANODE BEFORE TESTING WITH VIEW DOWN THE CONSTRICTOR.

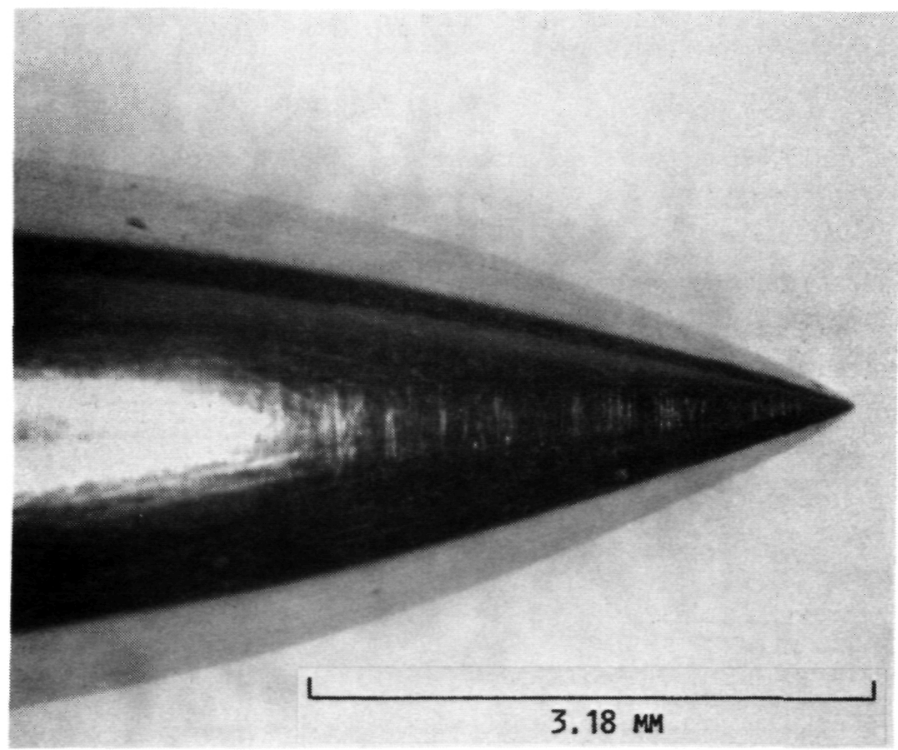

FIGURE 3. - PHOTOMICROGRAPH OF CATHODE TIP BEFORE TESTING. 


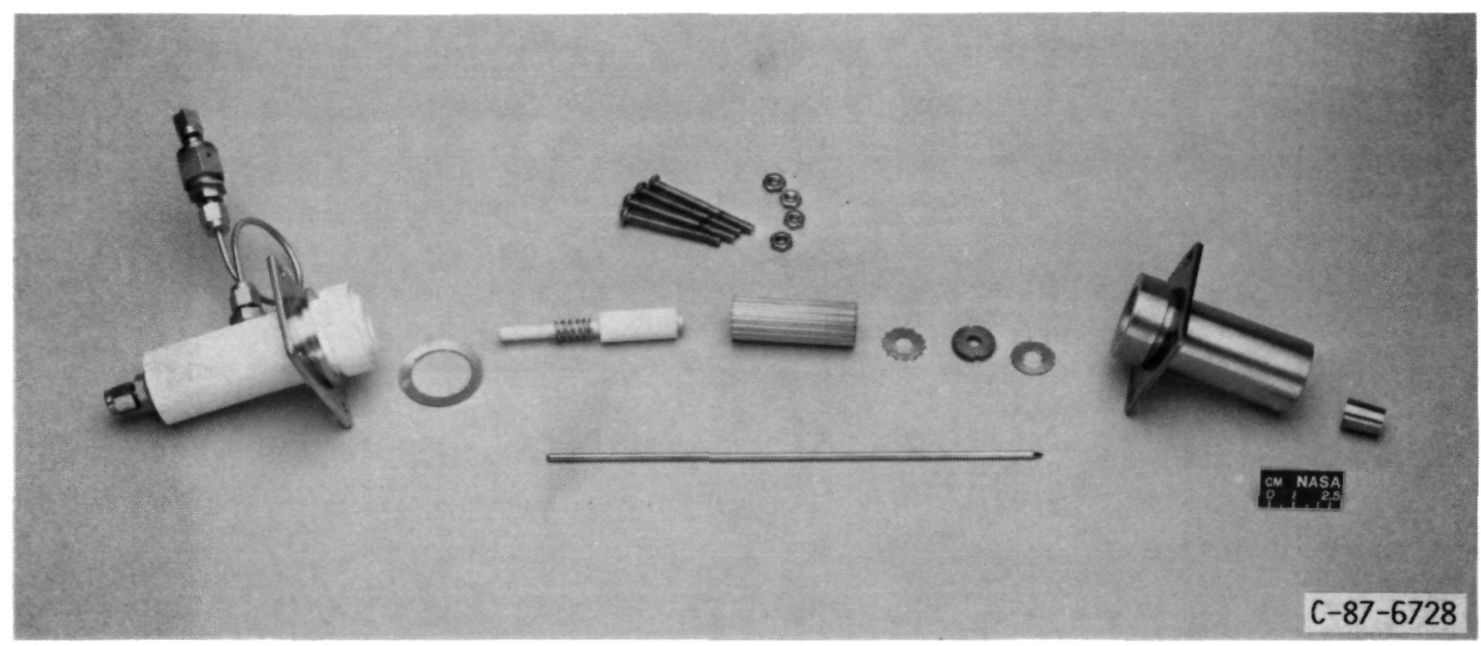

FIGURE 4. - DISASSEMBLED THRUSTER BEFORE START OF LIFE TEST.

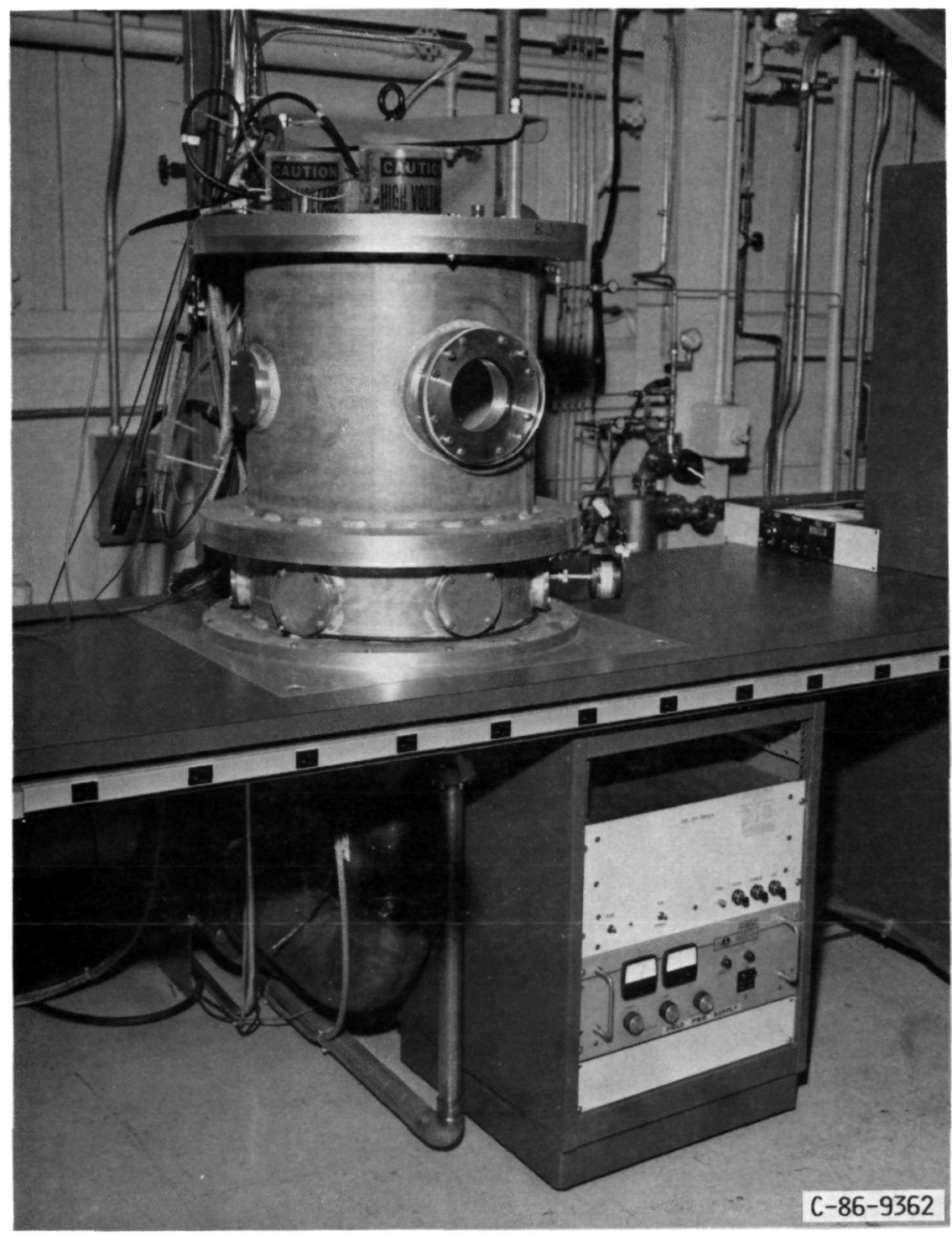

FIGURE 5. - VERTICAL BELL JAR TEST CHAMBER AND PULSE WIDTH MODULATED POWER SUPPLY BELOW). 


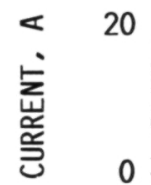

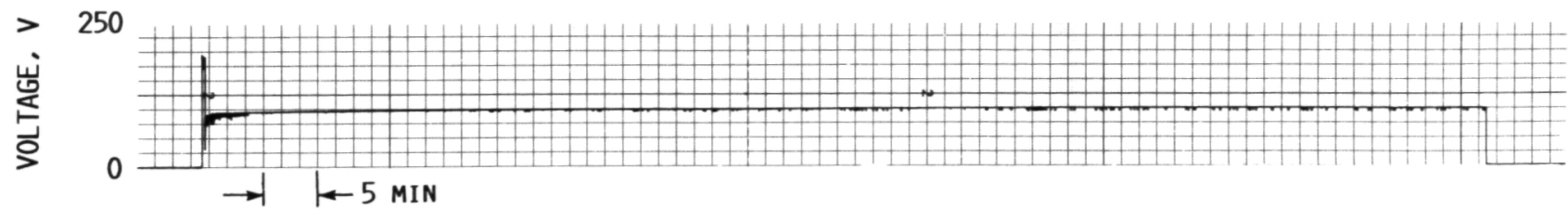

(A) CYCLE 9 - RAPID ARC VOLTAGE EXCURSIONS.
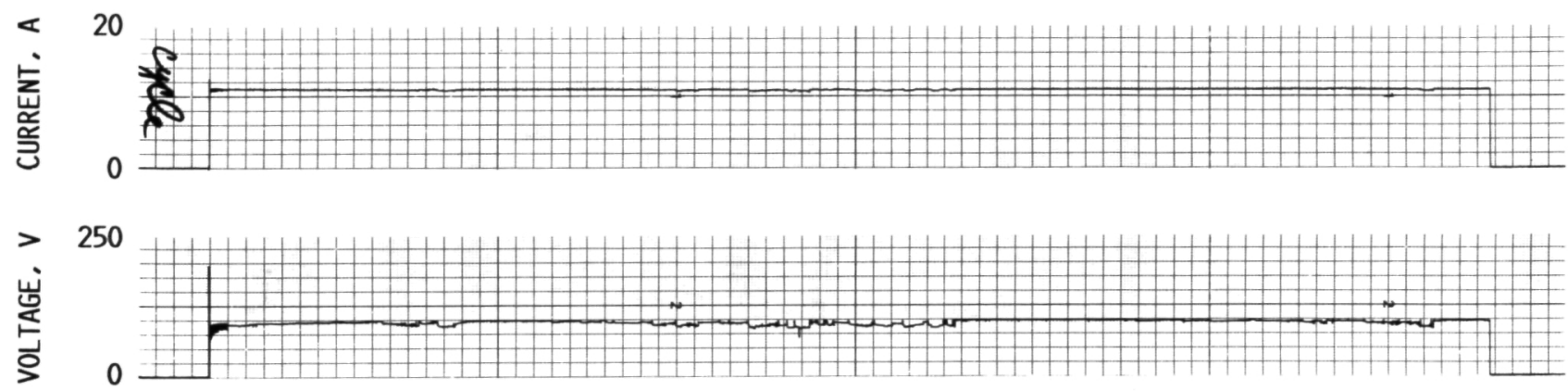

(B) CYCLE 13 - STEP CHANGES IN ARC VOLTAGE.

FIGURE 6. - VOLTAGE AND CURRENT TRACES SHOWING VOLTAGE EXCURSIONS DURING BURN-IN PERIODS.
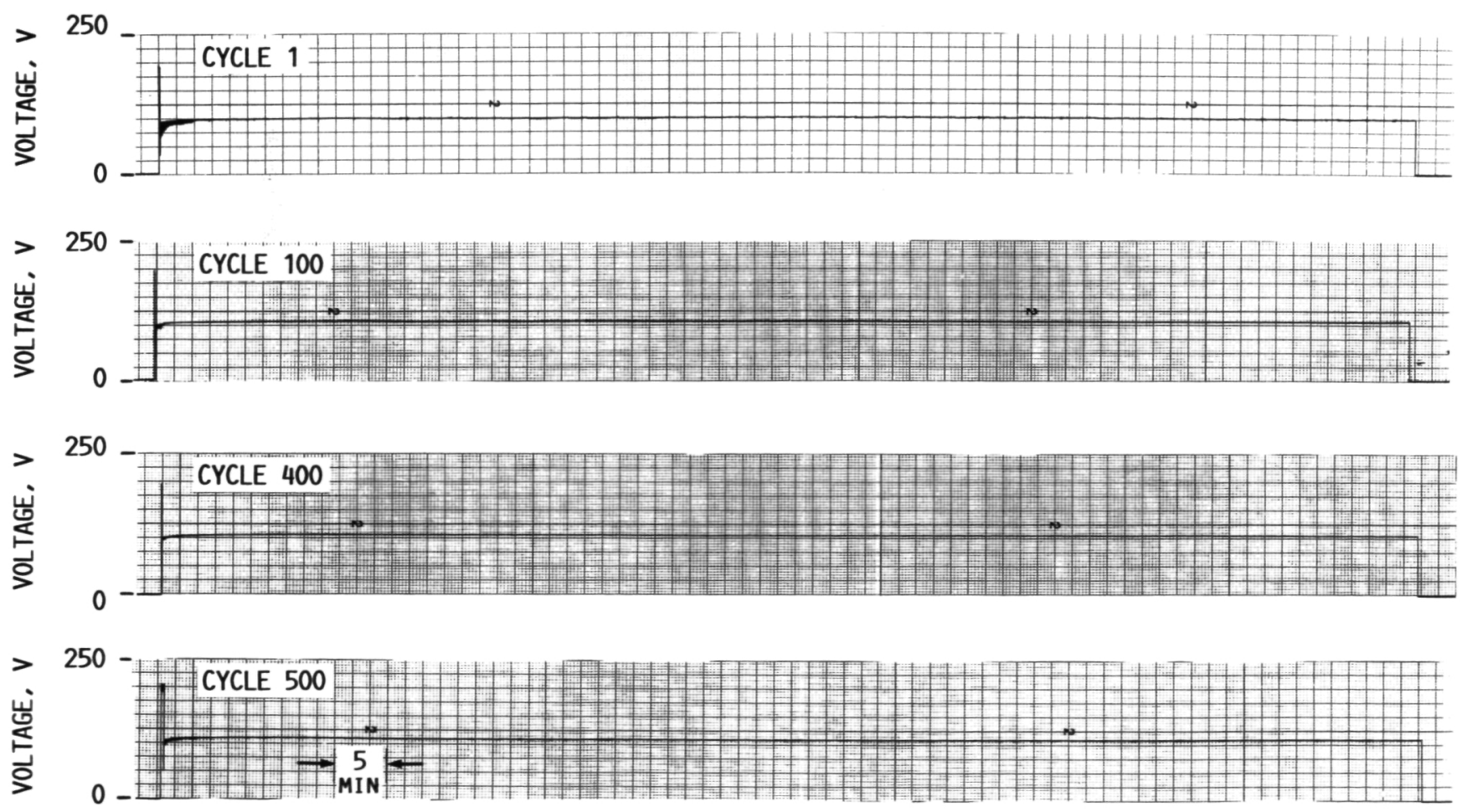

FIGURE 7. - STRIP CHART RECORDS OF REPRESENTATIVE CYCLES THROUGHOUT THE TEST. 


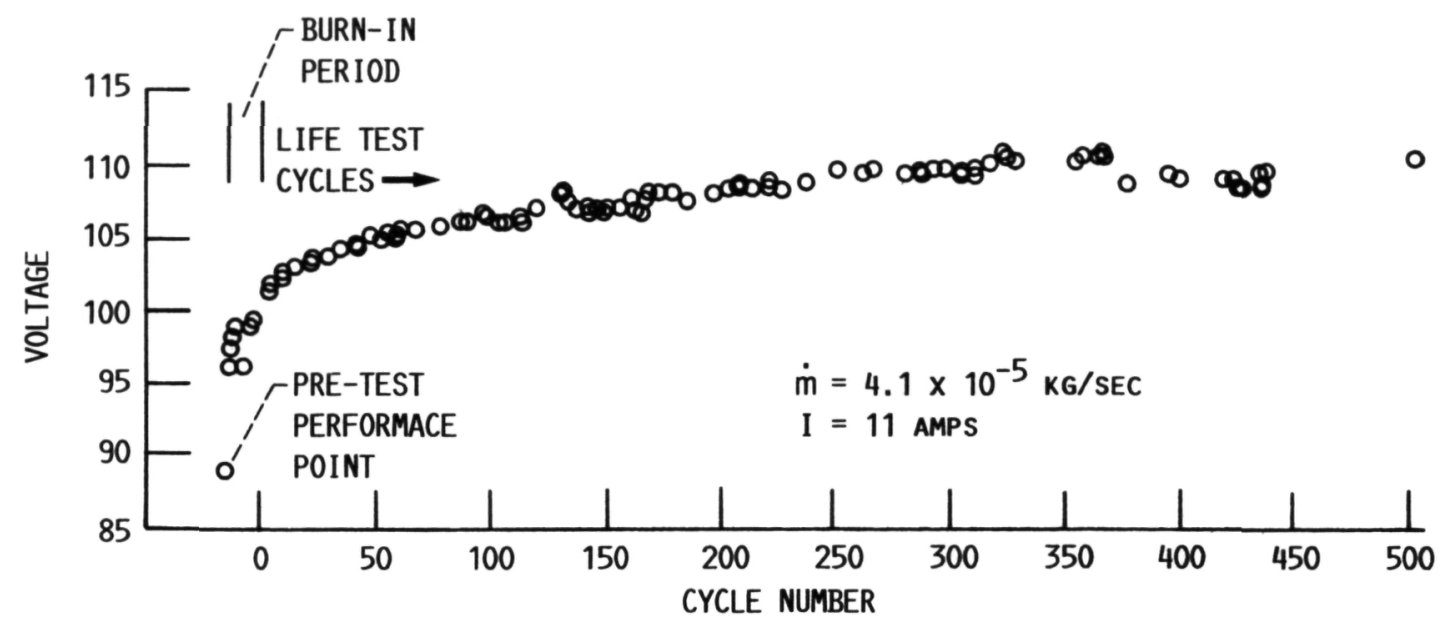

FIGURE 8. - ARC VOLTAGE VERSUS TIME AT A FIXED OPERATING POINT.

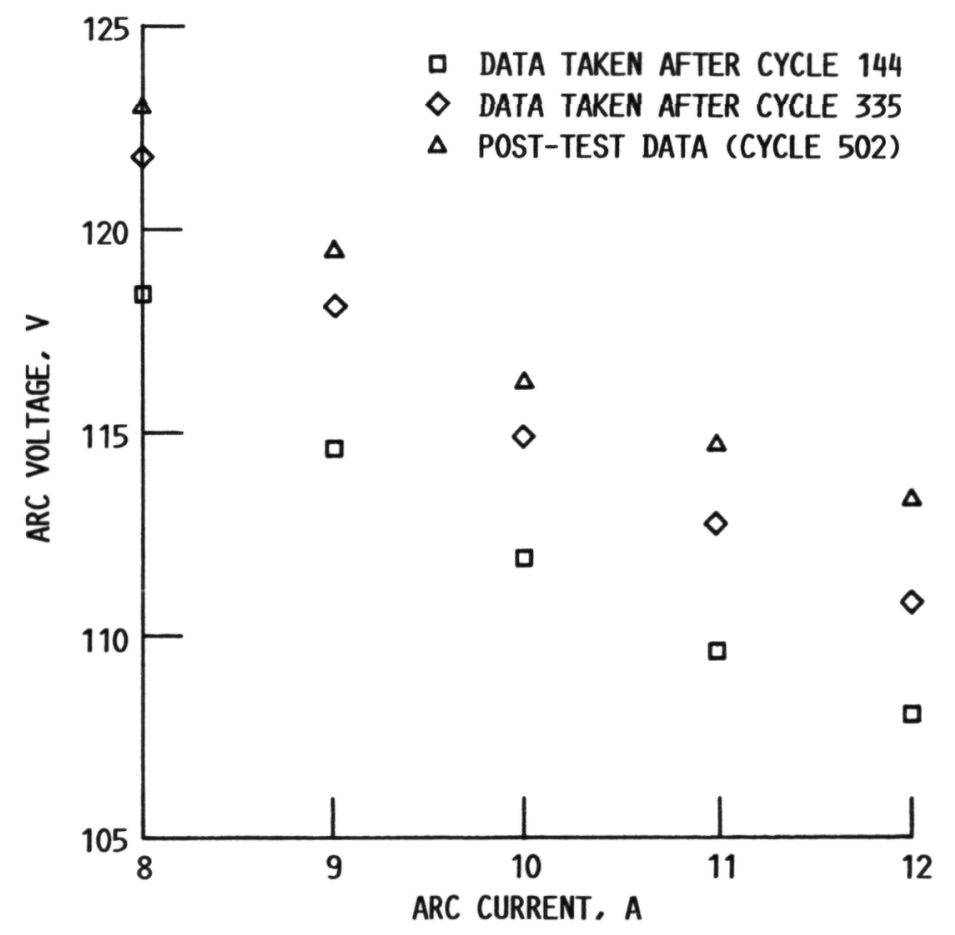

FIGURE 9. - ARC CURRENT-VOLTAGE CHARACTERISTICS DURING AND AFTER THE LIFE TEST $\left(\dot{m}=4.55 \times 10^{-5}\right.$ $K G / S E C)$. 


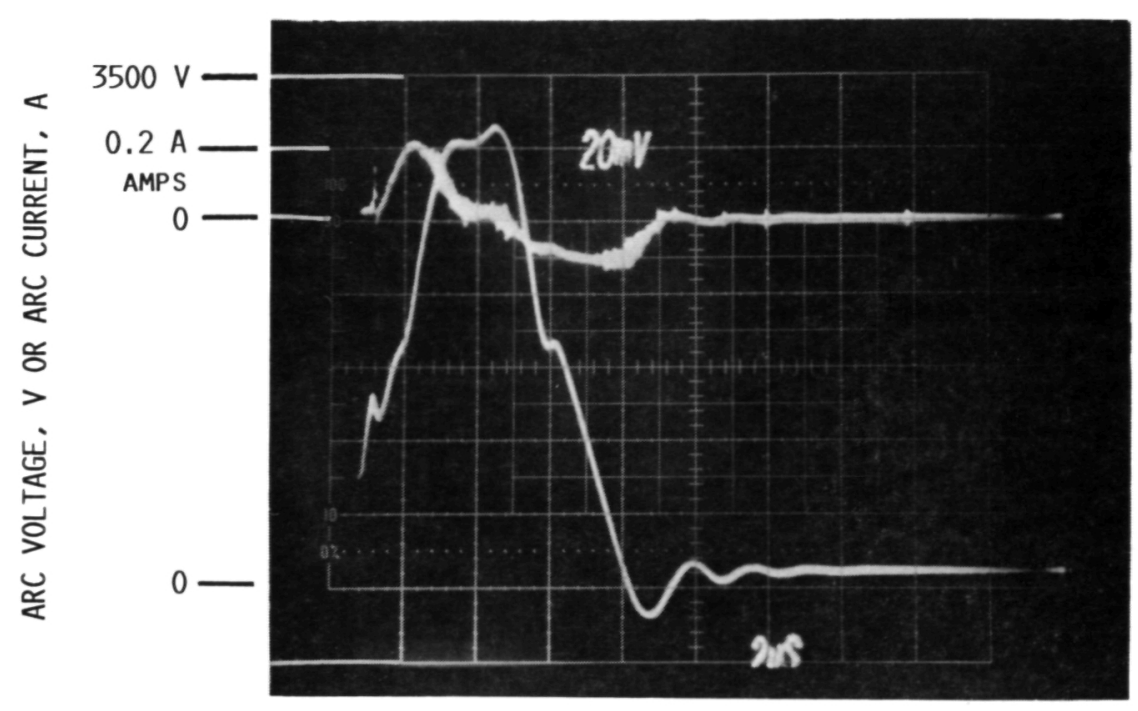

LOWER TRACE - DISTORTED HIGH VOLTAGE IGNITION PULSE UPPER TRACE - ARC-CURRENT

TIME SCALE - 2 MICROSECONDS/DIVISION

FIGURE 10. - OSCILLOSCOPE TRACE OF STARTING PULSE AND CURRENT CASE OF CORONA DISCHARGE.

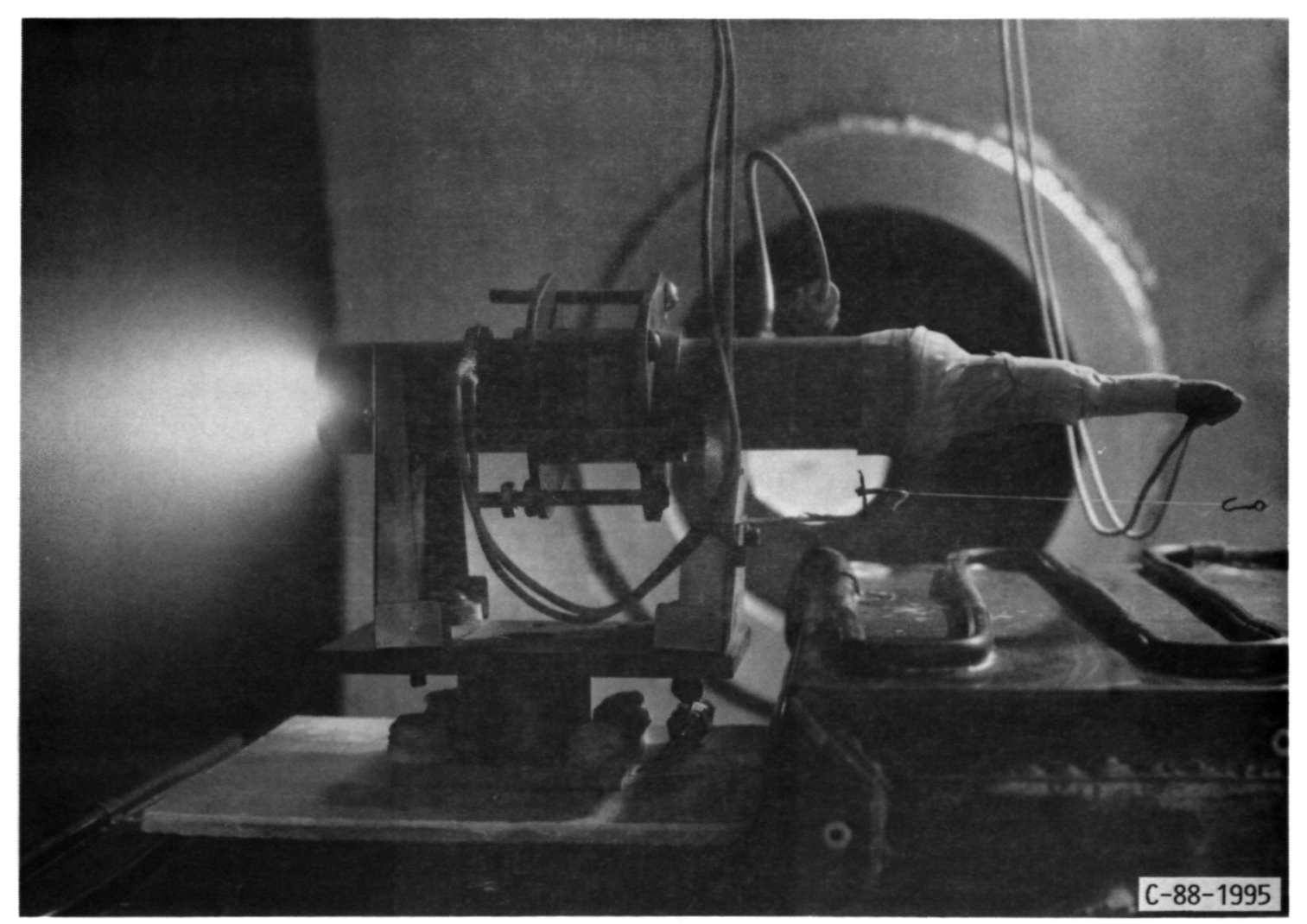

FIGURE 11. - ARCJET OPERATING IN FINAL PERFORMANCE CHECK. 


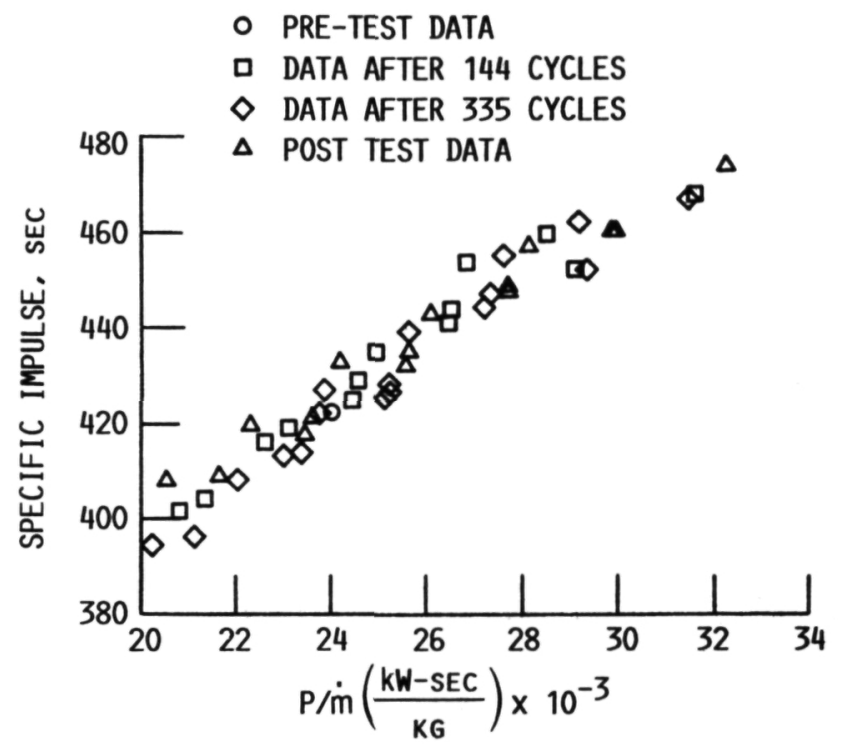

(A) SPECIFIC IMPULSE VESUS POWER TO MASS FLOW RATE RATIO.

FIGURE 12. - ARCJET PERFORMANCE DATA BEFORE, DURING AND AFTER THE LIFE TEST.

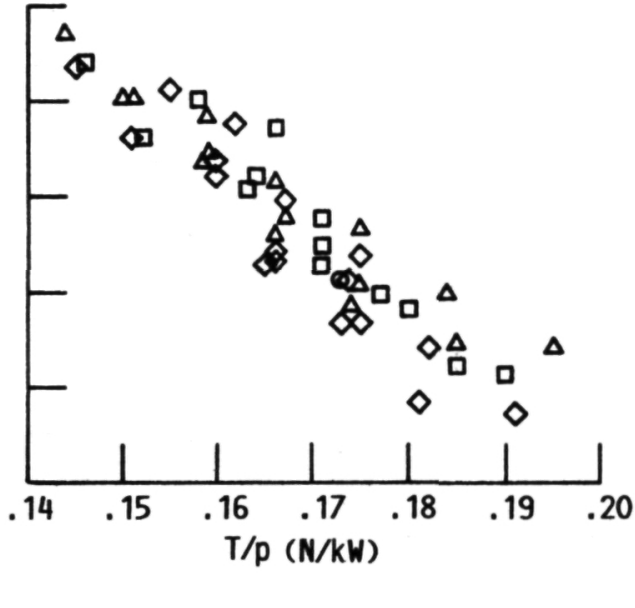

(B) SPECIFIC IMPULSE VERSUS THRUST TO POWER RATIO. 


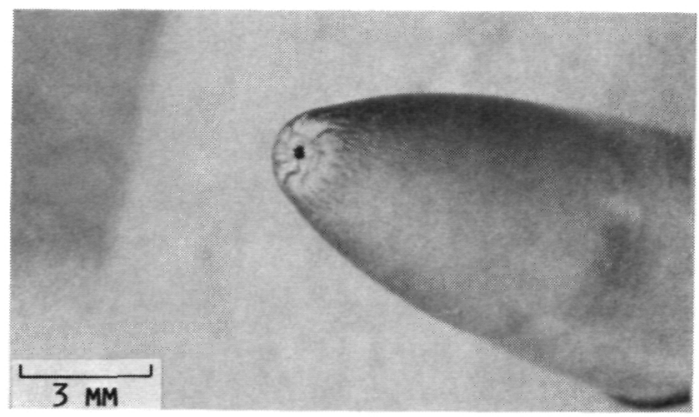

(A) CATHODE TIP.

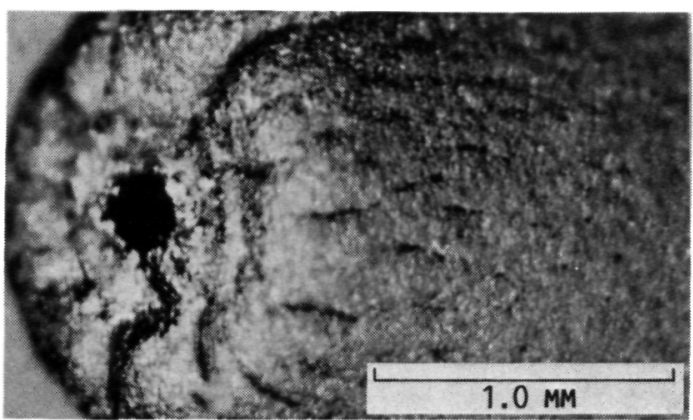

(B) CATHODE CENTER.

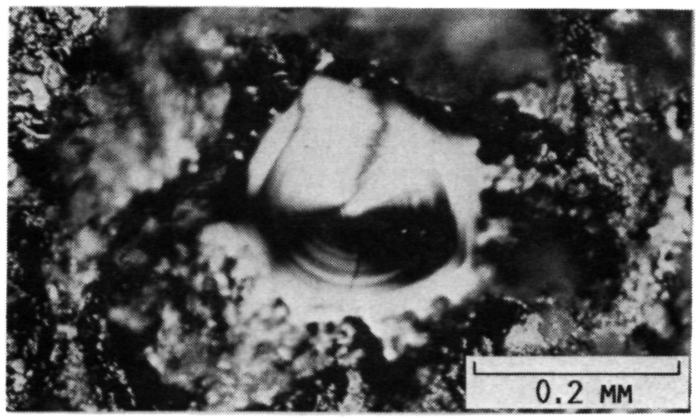

(C) MOLTEN POOL.

FIGURE 13. - POST-TEST CATHODE CONDITION.
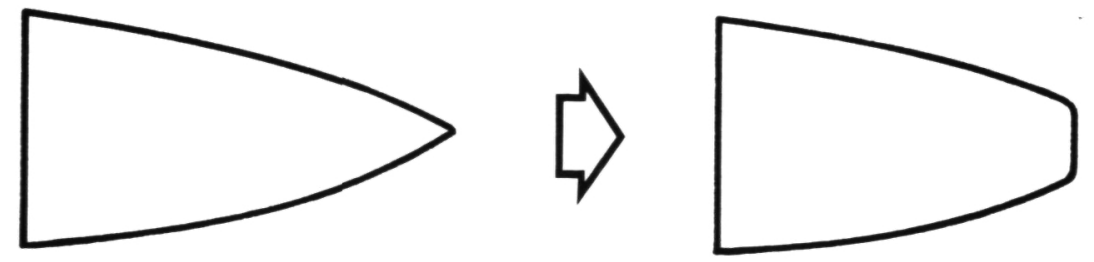

FIGURE 14. - CROSS-SECTIONAL SCHEMATIC OF THE CATHODE TIP RECESSION. 


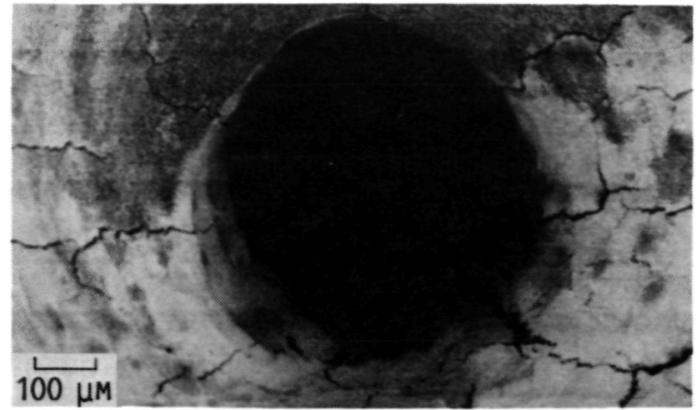

(A) CONVERGING SIDE OF NOZZLE.

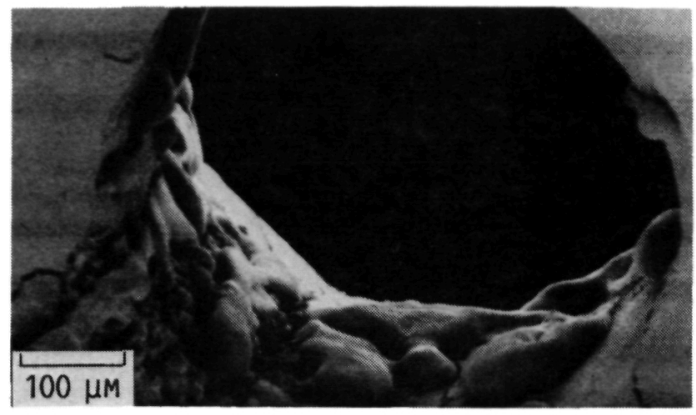

(B) DIVERGING SIDE OF NOZZLE.

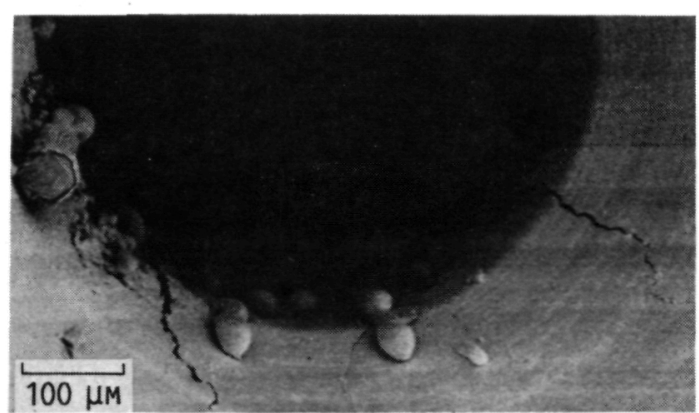

(C) DIVERGING SIDE OF NOZZLE.

FIGURE 15. - POST-TEST ANODE CONDITION. 


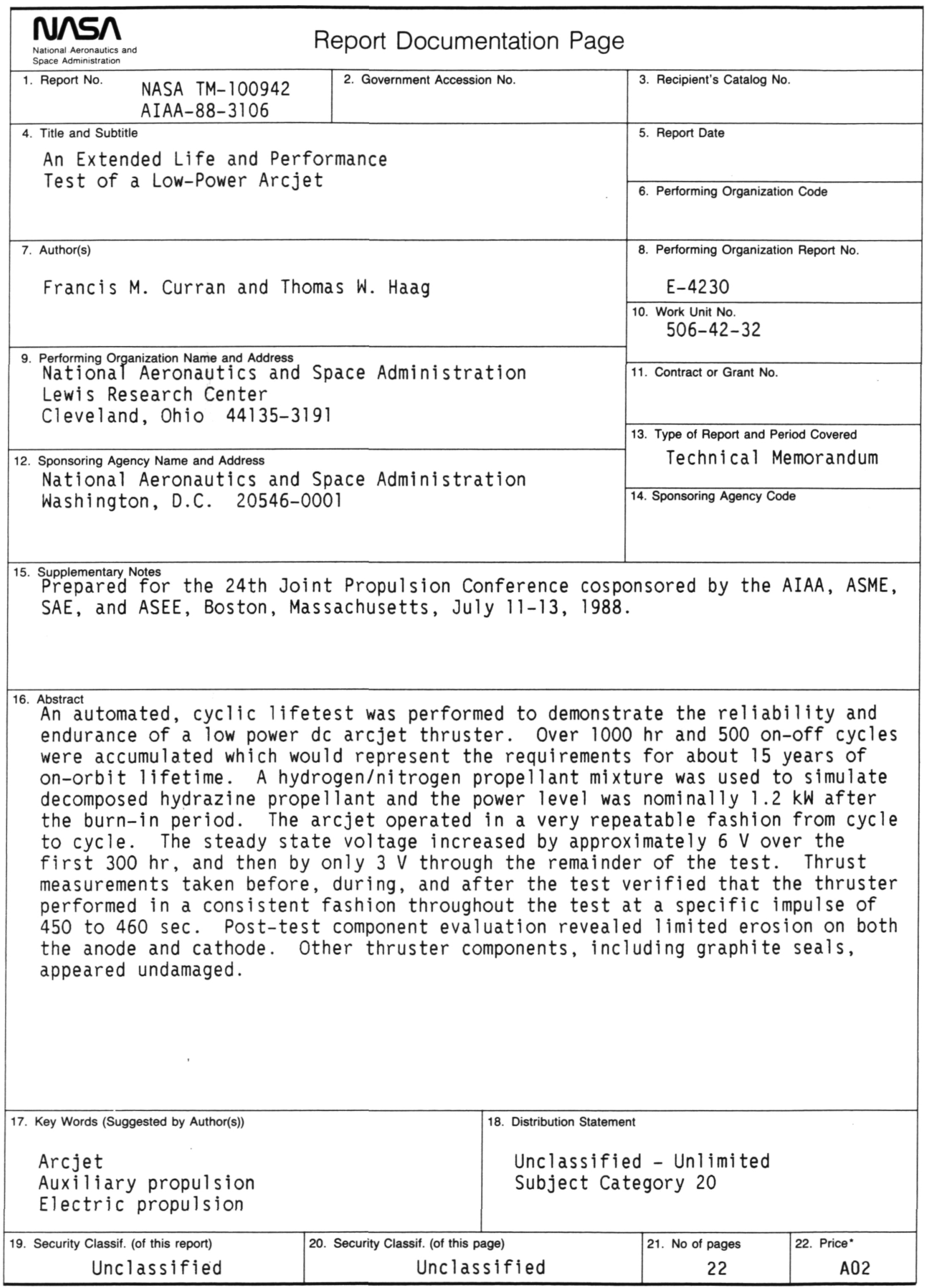

NASA TM- 100942

AIAA-88-3106

5. Report Date

Work Unit No.

506-42-32

Technical Memorandum

Sponsoring Agency Code 
National Aeronautics and

Space Administration

Lewis Research Center

Cleveland, Ohio 44135

Otficial Business

Penalty for Private Use $\$ 300$
FOURTH CLASS MAIL

ADDRESS CORRECTION REQUESTED
|||||

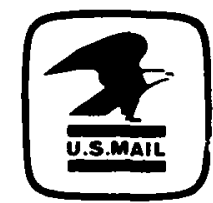

Postage and Fees Paid

Natıonal Aeronautics and

Space Administration

NASA 451 